\title{
Study on oligomerization of glutamate decarboxylase from Lactobacillus brevis using asymmetrical flow field-flow fractionation (AF4) with light scattering techniques
}

\author{
Jaeyeong Choi $^{1} \cdot$ Seungho Lee ${ }^{1} \cdot$ Javier A. Linares-Pastén $^{2} \cdot$ Lars Nilsson $^{3}$
}

Received: 15 August 2017 /Revised: 8 October 2017 / Accepted: 27 October 2017 /Published online: 22 November 2017

(C) The Author(s) 2017. This article is an open access publication

\begin{abstract}
In this work, asymmetrical flow field-flow fractionation (AF4) coupled with UV/Vis, multi-angle light scattering (MALS), and differential refractive index (dRI) detectors (AF4-UV-MALS-dRI) was employed for analysis of glutamate decarboxylase (LbGadB) from Lactobacillus brevis ( $L$. brevis). AF4 provided molecular weight $(M W)$ (or size)-based separation of dimer, hexamer, and aggregates of $L b \mathrm{GadB}$. The effect of $\mathrm{pH}$ on oligomerization of $L b \mathrm{GadB}$ was investigated, and then AF4 results were compared to those from molecular modeling. The $M W \mathrm{~s}$ measured by AF4-UV-MALS-dRI for dimeric and hexameric forms of $L b \mathrm{GadB}$ were 110 and $350 \mathrm{kDa}$, respectively, which are in good agreements with those theoretically calculated (110 and $330 \mathrm{kDa})$. The molecular sizes determined by AF4-UV-MALS-dRI were also in good agreement with those obtained from molecular modeling (6 and $10 \mathrm{~nm}$, respectively, for dimeric and hexameric from AF4-UV-MALS-dRI and $6.4 \times 7.6$ and $7.6 \times 13.1 \mathrm{~nm}$ from molecular modeling). The effects of temperature, salt type,
\end{abstract}

Electronic supplementary material The online version of this article (https://doi.org/10.1007/s00216-017-0735-6) contains supplementary material, which is available to authorized users.

Seungho Lee slee@hnu.kr

Javier A. Linares-Pastén javier.linares_pasten@biotek.lu.se

Lars Nilsson lars.nilsson@food.lth.se

1 Department of Chemistry, Hannam University, 1646 Yuseong-daero, Yuseong-gu, Daejeon 34054, Republic of Korea

2 Division of Biotechnology, Department of Chemistry, Lund University, Naturvetarvägen 16, 22362 Lund, Skåne, Sweden

3 Department of Food Technology, Engineering and Nutrition, Lund University, 22100 Lund, Sweden and salt concentration on oligomerization of $L b \mathrm{GadB}$ were also investigated using dynamic light scattering (DLS). It was found that the hexameric form of $L b \mathrm{GadB}$ was most stable at $\mathrm{pH} 6$ and in presence of $\mathrm{NaCl}$ or $\mathrm{KCl}$. The results indicate that $\mathrm{AF} 4$, in combination of various online detectors mentioned above, provides an effective tool for monitoring of oligomerization of $L b \mathrm{GadB}$ under different conditions, such as temperature, $\mathrm{pH}$, type of salts, and salt concentrations.

Keywords Glutamate decarboxylase (GAD) .

Oligomerization - Asymmetrical flow field-flow fractionation (AF4) $\cdot$ Multi-angle light scattering (MALS) $\cdot$ Lactobacillus brevis (L. brevis) · Probiotic

\section{Introduction}

Glutamate decarboxylase (GAD) catalyzes decarboxylation of glutamic acid giving $\gamma$-aminobutyric acid (GABA) (Fig. 1). GAD uses pyridoxal phosphate (PLP) as the co-factor and $\mathrm{H}^{+}$as the co-substrate. This enzyme is present in a variety of organisms, from bacteria to humans. GABA is one of the main neurotransmission inhibitors in the central nervous system. In addition, evidence exist that GABA can lower blood pressure in patients with mild hypertension and that it has other potential beneficial health effects, although mechanisms are not known yet $[1,2]$. While GABA is an attractive potential functional ingredient for food, chemically synthesized GABA is not accepted for use in food [3].

GABA is found in some fermented food, as for instance in kimchi [4]. Some strains of Lactobacillus brevis (L. brevis) were identified as GABA producers [3]. Due to its potential health effects in humans, L. brevis is recognized as a putative probiotic [5]. Thus, the potential production of GABA at 


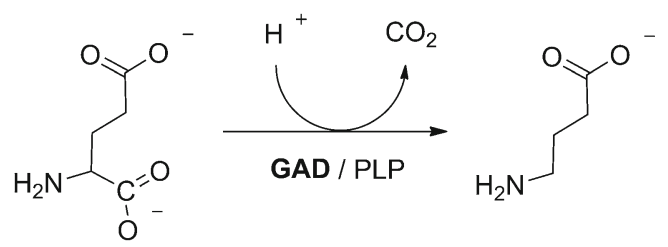

Fig. 1 Reaction catalyzed by the glutamate decarboxylase ( $L b \mathrm{GadB})$ in the presence of pyridoxal phosphate (PLP) as the co-factor

industrial levels using L. brevis as whole cell or its glutamate decarboxylase ( $L b \mathrm{GadB}$; notice that "GAD" represents the general name of glutamate decarboxylases present in a variety of organisms, while " $L b \mathrm{GadB}$ " represent specifically the glutamate decarboxylase from $L$. brevis) enzyme is very attractive. Therefore, there is great interest to understand the structure and function of $L b \mathrm{GadB}$. It was previously reported that the highest level of activity is reached when GAD is in the hexameric form, while the lowest was observed when GAD was present as a dimer [6,7]. Thus, oligomerization plays an important role in the GAD mechanism.

In general, size-exclusion chromatography (SEC), gel electrophoresis, and field-flow fractionation (FFF) are used to observe oligomerization of proteins.

SEC is commonly used for measurement of hydrodynamic size (or more commonly molecular weight, $M W$ ) based on size-based separation of analytes and their size distribution from calibration curve of standard samples or the multiangle light scattering (MALS) $[8,9]$. However, difficulties are frequently encountered when SEC is applied to high $M W$ analytes as they may undergo degradation by shear or they may be trapped in the SEC columns [10,11]. Furthermore, analytes may reach the column exclusion limit or the permeation limit leading to underestimation or overestimation of $M W$, in addition to blockage of the column [11, 12].

Asymmetrical flow field-flow fractionation (AF4) also provides separation of analytes based on their hydrodynamic sizes. In AF4, an open channel without packing material is used [13] and AF4 thus has several advantages over SEC. Due to the relatively gentle separation conditions in AF4 (i.e., low pressure and shear), degradation of analytes is prevented during separation. AF4 has been successfully used for the separation and characterization of high $M W$ analytes including proteins, DNA, viruses, and polysaccharides [14-17]. In addition, AF4 provides means to determine some physical properties, without calibration, such as $M W$, size, molecular density, and conformation when it is coupled online with the MALS.

The stability of the active hexameric form of GAD from L. brevis depends on several factors, including temperature, $\mathrm{pH}$, salt concentration, and type of salt. Thus, the study of the effect of these factors on the GAD oligomerization is fundamental to optimize the reaction conditions. In this work, the use of diverse techniques, such as AF4 coupled online with
MALS (AF4-MALS), dynamic light scattering (DLS), differential scanning fluorimetry (DSF), and molecular modeling methods, allows the integrated characterization of the main physicochemical factors that determine the stability of the oligomeric enzyme GAD.

\section{Material and methods}

\section{Materials}

Citric acid $\left(\mathrm{C}_{6} \mathrm{H}_{8} \mathrm{O}_{7}\right)$, sodium hydrogen phosphate anhydrous $\left(\mathrm{Na}_{2} \mathrm{HPO}_{4}\right)$, sodium chloride $(\mathrm{NaCl})$, potassium chloride $(\mathrm{KCl})$, calcium chloride $\left(\mathrm{CaCl}_{2}\right)$, ammonium sulfate $\left(\left(\mathrm{NH}_{4}\right)_{2} \mathrm{SO}_{4}\right)$, and sodium azide $\left(\mathrm{NaN}_{3}\right)$ were purchased from Sigma-Aldrich (St. Louis, USA).The carrier liquid for AF4 was prepared with water purified through a Milli-Q purification system (Millipore Co. Ltd., Billerica, USA, resistance $=18.2 \mathrm{M} \Omega / \mathrm{cm})$.

\section{Molecular cloning}

L. brevis DSM 1269 was purchased from the Leibniz Institute DSMZ-German Collection of Microorganisms and Cell Cultures. The strain was cultured in a MRS (Man, Rogosa, and Sharpe) medium at $30^{\circ} \mathrm{C}$ overnight after which genomic DNA was extracted using E.Z.N.A Genomic Isolation Kit (Omega Bio-Tek, USA). PCR primers, specific for GAD gene, were designed based on the genomic sequence of strain ATCC 367: Forward 5'-ATG ACG ACT ATC ATA TGA ATA AAA ACG ATC AGG AAA C-3' and reverse 5'-GTC AGC TGC CCC TCG AGA CTT CGA ACG GTG GTC-3' with restriction sites (underlined in the sequences) for NdeI and XhoI, respectively. The amplified gene was inserted in the protein expression vector $\mathrm{pET} 21 \mathrm{~b}$ giving the construct pET21b::LbGadB, which was introduced in Escherichia coli (E. coli) Origami 2 (DE3) (Novagen brand, Merck KGaA, Darmstadt, Germany). Recombinant E. coli was grown in $500 \mathrm{~mL}$ of LB (Luria Bertani) medium supplemented with $100 \mu \mathrm{g} / \mathrm{mL}$ ampicillin, at $37^{\circ} \mathrm{C}$. Recombinant $L b G a d B$ production was induced when the culture optical density (OD) at $\lambda=600 \mathrm{~nm}$ reaches 0.6 , with isopropyl $\beta$-D-1-thiogalactopyranoside, at $30{ }^{\circ} \mathrm{C}$ during $6 \mathrm{~h}$. Finally, the cell pelleted was harvested by centrifugation at $8000 \times g$ per $10 \mathrm{~min}$ in a Sorvall refrigerated centrifuge (RC5C, USA) for the recombinant protein purification.

\section{Protein purification}

Recombinant $L b \mathrm{GadB}$ was purified by ion-metal affinity chromatography. E. coli cell pellet was washed twice with binding buffer $\mathrm{pH} 7.4(50 \mathrm{mM}$ sodium phosphate, $0.5 \mathrm{M}$ $\mathrm{NaCl}$, and $20 \mathrm{mM}$ imidazole). Cell lysis was performed 
suspending $1 \mathrm{~g}$ of cell pellet in $5 \mathrm{~mL}$ BugBuster® Protein Extraction Reagent (San Diego, CA, USA) with $5 \mu \mathrm{L}$ Lysonase ${ }^{\mathrm{TM}}$ Bioprocessing Reagent and incubated for $30 \mathrm{~min}$ at $25^{\circ} \mathrm{C}$. Next, the suspension was centrifuged at $14,000 \times g$, the precipitate was discarded, and the supernatant was injected in a 5-mL HisTrap column FF (GE Healthcare, Uppsala, Sweden) previously equilibrated with binding buffer. After injection, the column was washed with binding buffer and the recombinant protein eluted with elution buffer $\mathrm{pH} 7.4$ (50 mM sodium phosphate, $0.5 \mathrm{M} \mathrm{NaCl}$, and $0.5 \mathrm{M}$ imidazole). Finally, the excess of $\mathrm{NaCl}$ was removed by dialysis in $50 \mathrm{mM}$ sodium phosphate buffer at $\mathrm{pH}$ 7.4. Protein purity was determined by SDS-PAGE and the concentration was quantified spectrophotometrically at $280 \mathrm{~nm}$.

\section{Molecular modeling}

Hybrid homology model of $L b G a d B$ was constructed using the YASARA software [18]. Crystallographic structures of other glutamate decarboxylases deposited in the Protein Data Bank (PDB codes: 3HBX, 1XEY, 1PMM, and $3 \mathrm{MAD}$, with amino acid sequence identities of 38 , 39,38 , and $23 \%$, respectively) were used as templates. The modeled structure was refined by molecular dynamic simulation using the AMBER03 force field [19]. The solvent was simulated with explicit molecules of water. Analysis of the modeled structure was done using UCSF Chimera v1.11.2 [20].

\section{Asymmetrical field-flow fractionation}

The asymmetrical flow field-flow fractionation (AF4) used in this work was an Eclipse 3+ system (Wyatt Technology, Dernbach, Germany) coupled online with a UV detector (UV-975, Jasco Corporation, Japan) set at $280 \mathrm{~nm}$, a multiangle light scattering (MALS) detector (DAWN HELEOS II, Wyatt Technology), and a differential refractive index (dRI) detector (Optilab T-rEX, Wyatt Technology). The AF4 channel was trapezoidal with the tip-to-tip length of $26.5 \mathrm{~cm}$ and the width at the inlet and outlet of 2.2 and $0.6 \mathrm{~cm}$, respectively, and was equipped with a $350-\mu \mathrm{m}$-thick Mylar spacer and a regenerated cellulose (RC) membrane (molecular weight cutoff of $10 \mathrm{kDa}$, Millipore, Bedford, USA).The AF4 carrier liquid with various $\mathrm{pH}$ (3 to 8 ) was $10 \mathrm{mM}$ citrate-phosphate buffer and was pumped into the AF4 channel using an Agilent 1200 HPLC pump equipped with an auto-sampler and an inline vacuum degasser (Agilent Technologies, Waldbronn, Germany). The channel flow rate was kept constant at $0.5 \mathrm{~mL} / \mathrm{min}$, while the cross flow rate was kept constant at $4.5 \mathrm{~mL} / \mathrm{min}$ for the first $20 \mathrm{~min}$; after which, it was exponentially decreased from 4.5 to $0.1 \mathrm{~mL} / \mathrm{min}$ with the half-life time of $2 \mathrm{~min}$ and then kept constant at $0.1 \mathrm{~mL} / \mathrm{min}$ for $30 \mathrm{~min}$. The channel was washed with the carrier liquid for $10 \mathrm{~min}$ without cross flow at the end of each run. All AF4 experiments were performed at room temperature. The collection and processing of AF4 data were performed using the ASTRA software (Version 6.1.1, Wyatt Technology) with the $d_{\mathrm{n}} / d_{\mathrm{c}}$ value of $0.185 \mathrm{~mL} / \mathrm{g}$. In all cases, the Berry method was used to fit the light scattering data $[21,22]$. From AF4 retention time, the hydrodynamic diameter $\left(d_{\mathrm{H}}\right)$ of a sample was calculated by the AF4 theory using the FFFHydRad 2.0 software [23, 24].

\section{Determination of thermal stability of $L b \mathrm{GadB}$}

Thermal stability of $L b \mathrm{GadB}$ in different $\mathrm{pH}$ values was determined using the Prometheus NT 48 nanoDSF (NanoTemper Technologies, GmbH, Munich Germany). Protein samples were prepared in $\mathrm{pH}$ 4, 5, 6, 7, 8 (Mcllvaine buffer system, $100 \mathrm{mM}$ ), and 9.6 (glycin- $\mathrm{NaOH}$ buffer, $100 \mathrm{mM}$ ). The capillaries were directly filled with $10 \mu \mathrm{L}$ of every sample. Intrinsic fluorescence at emission wavelengths of 330 and $350 \mathrm{~nm}$ was monitored in a temperature gradient from 20 to $90{ }^{\circ} \mathrm{C}$. All data analysis was performed using the PR control software (Version 2.0, Munich Germany).

\section{Dynamic light scattering}

The dynamic light scattering (DLS) analysis was performed using DynaPro Plate Reader II (Wyatt Technology) equipped with a laser with the wavelength of $830 \mathrm{~nm}$ as the light source. The analysis conditions were as follows: temperature $=25,37$, 45 , and $60{ }^{\circ} \mathrm{C}$; accumulation time $=100 \mathrm{~s}$; and number accumulation $=10$. The $L b G a d B$ was prepared using various salt types $\left(\mathrm{NaCl}, \mathrm{KCl}, \mathrm{CaCl}_{2}\right.$, and $\left.\left(\mathrm{NH}_{4}\right)_{2} \mathrm{SO}_{4}\right)$ at concentrations $(0,0.3,0.6,0.9$, and $1.2 \mathrm{M})$. Each sample of $60 \mu \mathrm{L}$ was put in the supported 384-well plate before DLS analysis.

\section{Results and discussion}

\section{Protein production}

Glutamate decarboxylase gene from $L$. brevis DSM 1269 was cloned and the recombinant protein was successfully produced in E. coli. The gene was sequenced and deposited in the GenBank (accession code: KX417371). The protein sequence was obtained by theoretical translation of the gene. The protein sequence was identical to the $L b \mathrm{GadB}$ of the strain ATCC 367. The $M W$ of the monomer was determined experimentally by SDS-PAGE (see Fig. 2) and theoretically from the protein sequence, giving the consistent value of $54.5 \mathrm{kDa}$. 
M Ext. LbGadB

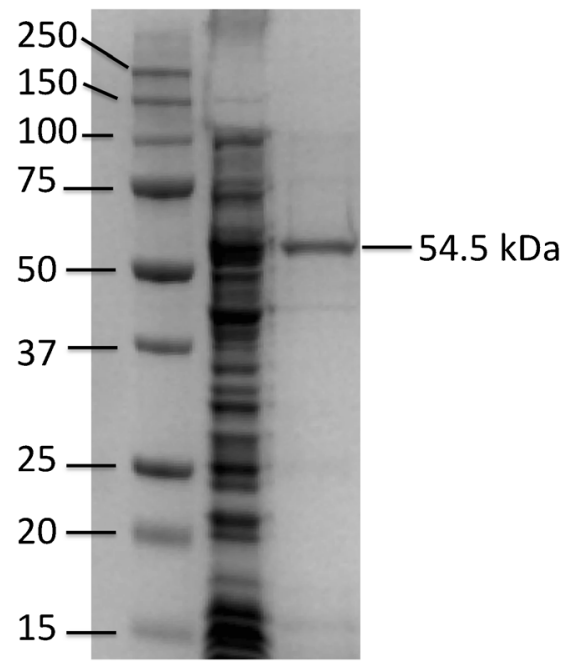

Fig. 2 Expression and purification of $L b \mathrm{GadB}$ from L. brevis DSM 1269

\section{Molecular modeling}

The molecular model was obtained in the hexameric form, which is a trimer of dimers. The overall structure has two layers, where every dimer contributes with one subunit to each layer. Ramachandran plot analysis showed that $94.5 \%$ of the amino acids were in the preferred regions, $5 \%$ in the allowed regions, and $0.5 \%$ were outliers; this suggests that the model is acceptable. The dimer dimension was $6.4 \times 7.6 \mathrm{~nm}$, while the hexamer diameter was $13.1 \mathrm{~nm}$ and the width was $7.6 \mathrm{~nm}$ (Fig. 3).
Effect of the pH in the oligomerization of $L b$ GadB: AF4 studies

Figure 4 shows AF4-UV-MALS fractograms of the recombinant $L b \mathrm{GadB}$ obtained at various $\mathrm{pH}$. Figure $4 \mathrm{a}$ shows the LS responses (measured at $90^{\circ}$ ) and the molecular weight distributions $(M W D)$. Figure $4 \mathrm{~b}$ shows the same fractograms as those in Fig. $4 \mathrm{a}$ at the retention time of $0 \sim 20 \mathrm{~min}$. The UV responses are shown in Fig. 4c. As shown in Fig. $4 \mathrm{a}-\mathrm{c}$, at pH 7 and 8 , the dimers of $L b \mathrm{GadB}$ are eluted at $\sim 7 \mathrm{~min}$. At $\mathrm{pH} 6$, hexamers are formed, and thus the elution time was increased ( $\sim 9 \mathrm{~min})$. Also a broad band was observed at $\mathrm{pH} 6$ at around $30 \mathrm{~min}$, probably due to elution of $L b \mathrm{GadB}$ aggregates. When $\mathrm{pH}$ was further lowered down to 5 and then 4 , the intensity of the broad band at around $30 \mathrm{~min}$ increases, due to more aggregation, with no distinct hexamer peak observed. It is noted, at $\mathrm{pH} 3$, the intensity of the broad band was decreased, and a tailed band was observed at the elution time of around $5 \mathrm{~min}$, which is due to large aggregates eluting in the steric/ hyperlayer mode $[25,26]$. As shown in Fig. 4b, the molecular weight decreases with increasing time for the tailed band, which confirms the aggregates are eluted by the steric/ hyperlayer mode. The average $M W$ of the tailed band at 5 min was $5.7 \times 10^{8}$ Da by determined by MALS, which is much higher than the average $M W\left(1.1 \times 10^{5} \mathrm{Da}\right)$ of the $7-\mathrm{min}$ peak observed at $\mathrm{pH} 8$.

The $M W$ of the dimer and the hexamer of recombinant $L b$ GadB were determined to be 110 and $350 \mathrm{kDa}$ at $10 \mathrm{mM}$ citrate-phosphate buffer of $\mathrm{pH} 8$ and 6, respectively, by AF4MALS. These $M W$ values are in agreement with those
Fig. 3 Molecular models of LbGadB: a dimer and $\mathbf{b}$ hexamer a
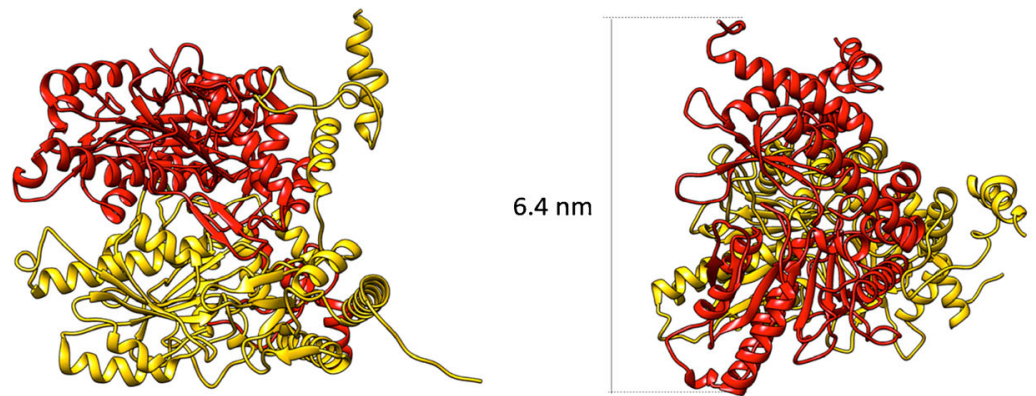

b

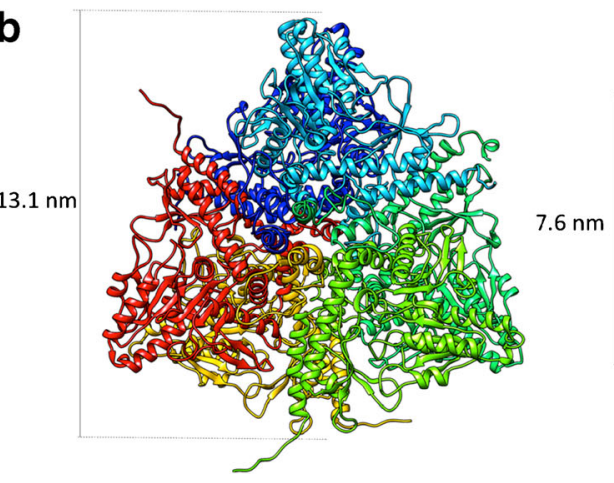

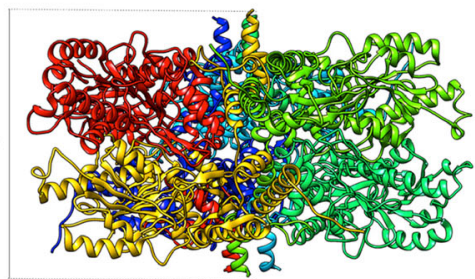



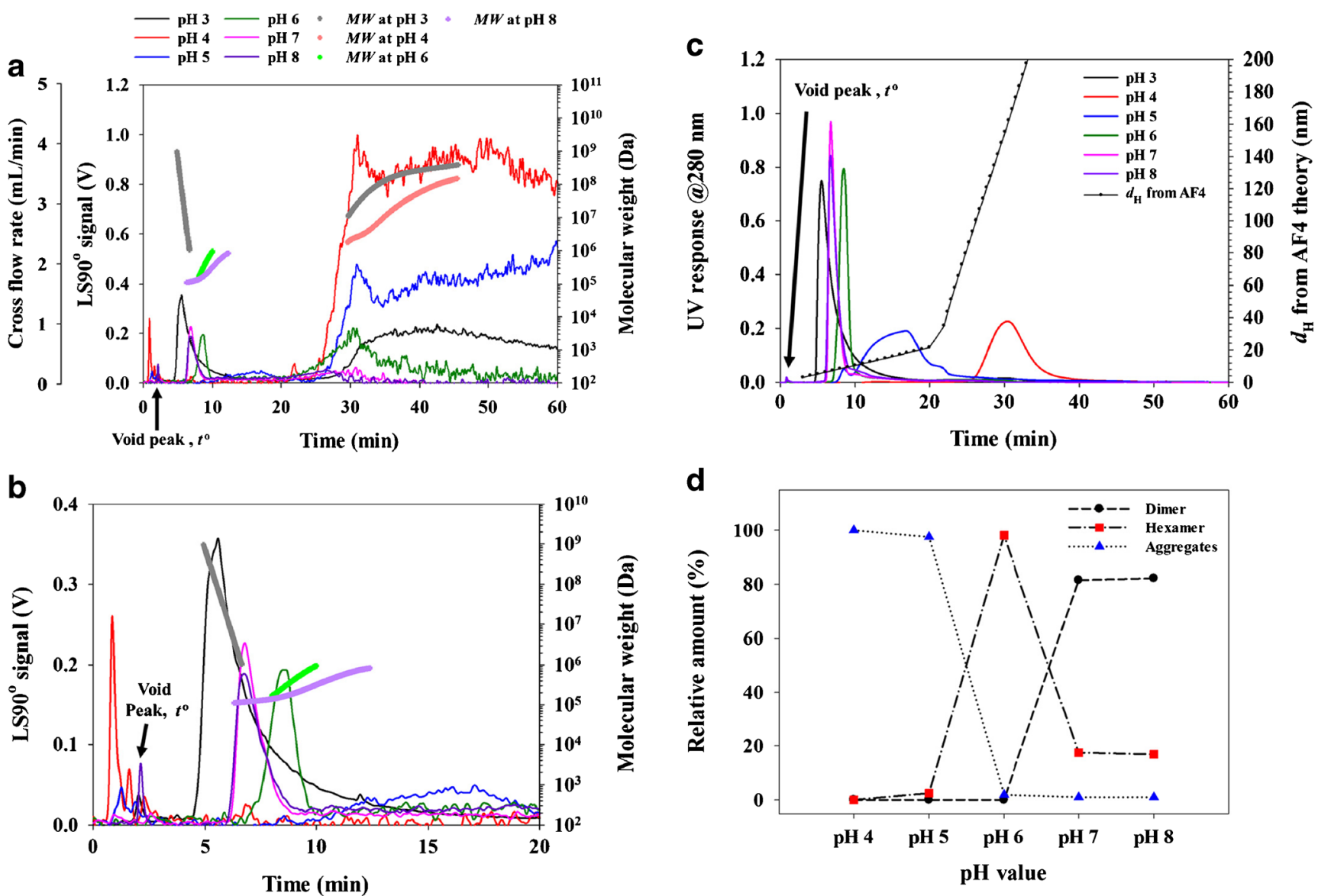

Fig. 4 AF4-MALS-UV fractograms of $L b \mathrm{GadB}$ obtained at various $\mathrm{pH}$. The injection volume was $200 \mu \mathrm{L}$ at $\mathrm{pH} 3$ and 4 and $150 \mu \mathrm{L}$ at $\mathrm{pH} 5,6,7$, and 8. a LS fractogram at $90^{\circ}$ and $M W$. b Enlargement of fractogram

shown in a. c UV fractogram at $280 \mathrm{~nm}$ and $d_{\mathrm{H}}$ from AF4 theory. d Relative amount of dimer, hexamer, and aggregates of $L b \mathrm{GadB}$ measured from peak area of deconvoluted UV fractograms

measured for the $L b \mathrm{GadB}$ monomer, $55 \mathrm{kDa}$ by SDS-PAGE and molecular modeling.

The radius of gyration $\left(r_{\mathrm{g}}\right)$ of the dimer and the hexamer of the $L b \mathrm{GadB}$ could not be measured by MALS as the analytes behaved as isotropic scatterers, and hence, no angular dependence in the scattered light is observed. The $d_{\mathrm{H}}$ was determined using AF4 theory $[23,24]$ and were compared with results obtained from molecular modeling for the dimer and the hexamer of $L b \mathrm{GadB}$. From the AF4 theory, the $d_{\mathrm{H}}$ of the dimer and the hexamer of $L b \mathrm{GadB}$ were determined to be 6 and $10 \mathrm{~nm}$,

respectively, and were in reasonable agreement with those from molecular modeling, which were $6.4 \times 7.6 \mathrm{~nm}$ for the dimer and $7.6 \times 13.1 \mathrm{~nm}$ for the hexamer. The sizes determined by AF4 theory and modeling are not expected to be identical, as they have different physical meanings, i.e., the $d_{\mathrm{H}}$ determined by AF4 is the molecular size obtained from the diffusion coefficient (through the Stokes-Einstein equation) [27]. While, the sizes calculated from homology model are based on its atomic three-dimensional structure built using as templates crystallographic structures of homologous proteins [19].

Table 1 Molecular weight $(M W)$ and size of recombinant $L b \mathrm{GadB}$ determined from peak maximum point of $\mathrm{pH} 4,6$, and 8 by various methods

\begin{tabular}{lllll}
\hline Form of $L b G a d B$ & Molecular weight $(\mathrm{Da})$ & Radius of gyration, $r_{\mathrm{g}}(\mathrm{nm})$ & $\begin{array}{l}\text { Hydrodynamic } \\
\text { diameter, } d_{\mathrm{H}}(\mathrm{nm})\end{array}$ & Molecular dimension ${ }^{\mathrm{a}}(\mathrm{nm})$ \\
\hline Dimer & $1.1 \times 10^{5}$ & n.d & 6 & $6.4 \times 7.6$ \\
Hexamer & $3.5 \times 10^{5}$ & n.d & 10 & $7.6 \times 13.1$ \\
Aggregates & $1.8 \times 10^{6} \sim 2.2 \times 10^{8}$ & $70 \sim 78$ & $80 \sim 292$ & n.d \\
\hline
\end{tabular}

n.d = no data

${ }^{\text {a }}$ Molecular modeling result 
Table 2 Relative concentration of monomer, hexamer, and aggregate of $L b \mathrm{GadB}$ obtained by deconvolution of $\mathrm{UV}$ fractograms at various $\mathrm{pH}$

\begin{tabular}{lllc}
\hline $\mathrm{pH}$ & \multicolumn{2}{l}{ Concentration $(\%)$} & \\
\cline { 2 - 4 } & Dimer & Hexamer & Aggregates \\
\hline 4 & - & - & 100 \\
5 & - & 3 & 97 \\
6 & - & 98 & 2 \\
7 & 81 & 18 & 1.0 \\
8 & 82 & 17 & 1.0 \\
\hline
\end{tabular}

Table 1 shows the $M W$ and size determined by various methods for recombinant $L b G a d B$. In Table 1 , the $M W$ and $r_{\mathrm{g}}$ were determined by MALS, $d_{\mathrm{H}}$ were determined by AF4 theory, and molecular dimensions by modeling, respectively.

In general, proteins show UV absorption at $280 \mathrm{~nm}$ due to UV absorbing amino acid, such as tryptophan, tyrosine, and phenylalanine. However, the large aggregates cause scattering effects, so correction of the results is necessary such as deconvolution for quantitative analysis. Thus, all results of UV detector were deconvoluted to dimer, hexamer, and aggregates for semi-quantitative analysis of oligomerization of $L b$ GadB. Figure $4 \mathrm{~d}$ and Table 2 show the relative percent concentration of the dimer, hexamer, and aggregates of recombinant $L b$ GadB obtained by deconvoluting the UV fractograms in Fig. 4c using the PeakFit software (ver. 4.0, Systat Software Inc., San Jose, USA) with the Savitsky-Golay smoothing.

Consistent with previous studies of plant (Arabidopsis thaliana) glucatamate decarboxylase (AtGAD1) [6], it seems that $L b G a d B$ from $L$. brevis is stable in a dimer form at $\mathrm{pH} 7$ or higher. In Fig. $4 \mathrm{~d}$ and Table 2, only $18 \%$ of $L b \mathrm{GadB}$ are present in a hexamer form at $\mathrm{pH} 7$. The $L b \mathrm{GadB}$ is present mostly as hexamer at $\mathrm{pH}$ 6. Then at $\mathrm{pH} 5$ or lower, most of $L b \mathrm{GadB}$ are present as aggregates

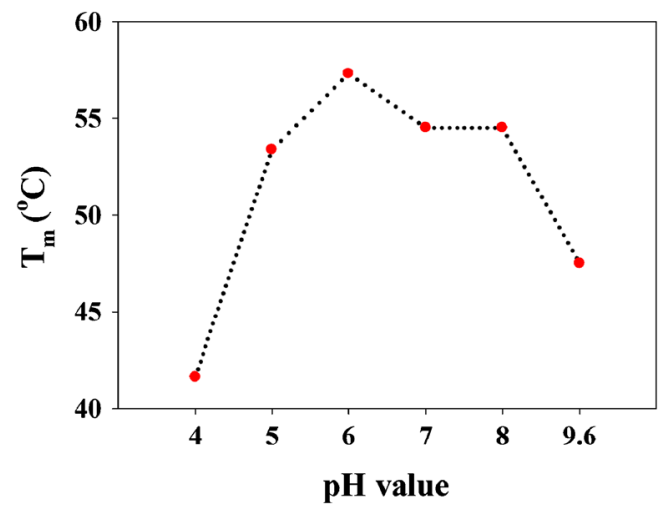

Fig. 5 Thermal stability of $L b \mathrm{GadB}$ described by the thermal unfolding transition midpoint $\left(T_{\mathrm{m}}\right)$ in different $\mathrm{pH}$ values
(98\% at $\mathrm{pH} 5$ and $100 \%$ at $\mathrm{pH}$ 4), indicating the hexamer of $L b \mathrm{GadB}$ is not stable at $\mathrm{pH}$ below about 5 . The isoelectric point ( $\mathrm{pI}$ ) of $L b \mathrm{GadB}$ calculated by the molecular modeling was 5.15 in the present study and aggregation of $L b \mathrm{GadB}$ will be promoted at $\mathrm{pH}$ below $\mathrm{pI}$. The hexamer concentration changes drastically from $18 \%$ at $\mathrm{pH} 7$ to $98 \%$ at $\mathrm{pH} 6$.

It has been reported that $A t \mathrm{GAD} 1$ is present mostly as hexamer at $\mathrm{pH}$ below 7 [6]; in this line, our results show that the hexameric form of $L b \mathrm{GadB}$ is more stable at pH 6 than pH 7. Both enzymes, AtGAD1 and LbGadB, share $38 \%$ of amino acid sequence identity (query cover of $94 \%$, BLAST search). The thermal stability of $L b \mathrm{GadB}$ in different $\mathrm{pHs}$ shows the maximum stability at $\mathrm{pH} 6\left(T_{\mathrm{m}} 57^{\circ} \mathrm{C}\right)$ and the lowest at $\mathrm{pH} 4\left(T_{\mathrm{m}} 46^{\circ} \mathrm{C}\right)$ (Fig. 5). At $\mathrm{pH} \mathrm{6,} \mathrm{the} \mathrm{main} \mathrm{form} \mathrm{is} \mathrm{the} \mathrm{hexamer,} \mathrm{which}$ means that this oligomeric form is the most stable form, while at $\mathrm{pH} 4$ almost all of the protein aggregate (Fig. 4d). At pHs 7 and 8, the predominant form is the dimer, which is less stable than the hexamer since the thermal unfolding transition midpoint $\left(T_{\mathrm{m}} 54{ }^{\circ} \mathrm{C}\right)$ is lower in both pHs (Fig. 5). The dimer and hexameric forms are stabilized by hydrogen-bonding interactions; therefore, the thermal stability is increased [28, 29]. While, in the case of the aggregates, it is expected that is not thermally stable because it is mostly formed physically with low or without hydrogen-bonding interactions. Thus, the results of AF4 and thermal stability mean $L b G a d B$ has most stable form occurs at $\mathrm{pH}$ 6. It is new discovery for oligomerization of $L b \mathrm{GadB}$.

\section{Effect of type and concentration of salt and temperature on oligomerization of $\mathrm{LbGadB}$}

Figure 6 shows the $d_{\mathrm{H}}$ of $L b \mathrm{GadB}$ determined by DLS with four different types of salts $\left(\mathrm{NaCl}, \mathrm{KCl}, \mathrm{CaCl}_{2}\right.$, and $\left.(\mathrm{NH} 4)_{2} \mathrm{SO}_{4}\right)$ added at five different concentrations $(0$, $0.3,0.6,0.9$, and $1.2 \mathrm{M}$ ) at four different temperatures $\left(25,37,45\right.$, and $\left.60{ }^{\circ} \mathrm{C}\right)$. These salts are generally recognized as safe (GRAS) according to Food and Drug Administration (FDA). All results show a similar trend of an increase in $d_{\mathrm{H}}$ with an increase of salt concentration or temperature. At the lower temperatures (25 and $37{ }^{\circ} \mathrm{C}$ ), however, no significant changes in $d_{\mathrm{H}}$ were observed by a change in the salt concentration. Similarly, at the lower salt concentrations (0 and $0.3 \mathrm{M})$, no significant changes in $d_{\mathrm{H}}$ were observed by a change in the temperature. The effect by the salt type was not clear. Based on the results at $37{ }^{\circ} \mathrm{C}$ (see Electronic Supplementary Material (ESM) Fig. S1 for more details), the hexameric form of $L b \mathrm{GadB}$ is most stable in $\mathrm{NaCl}$ or $\mathrm{KCl}$ and is not affected by the salt concentration in the investigated range. 

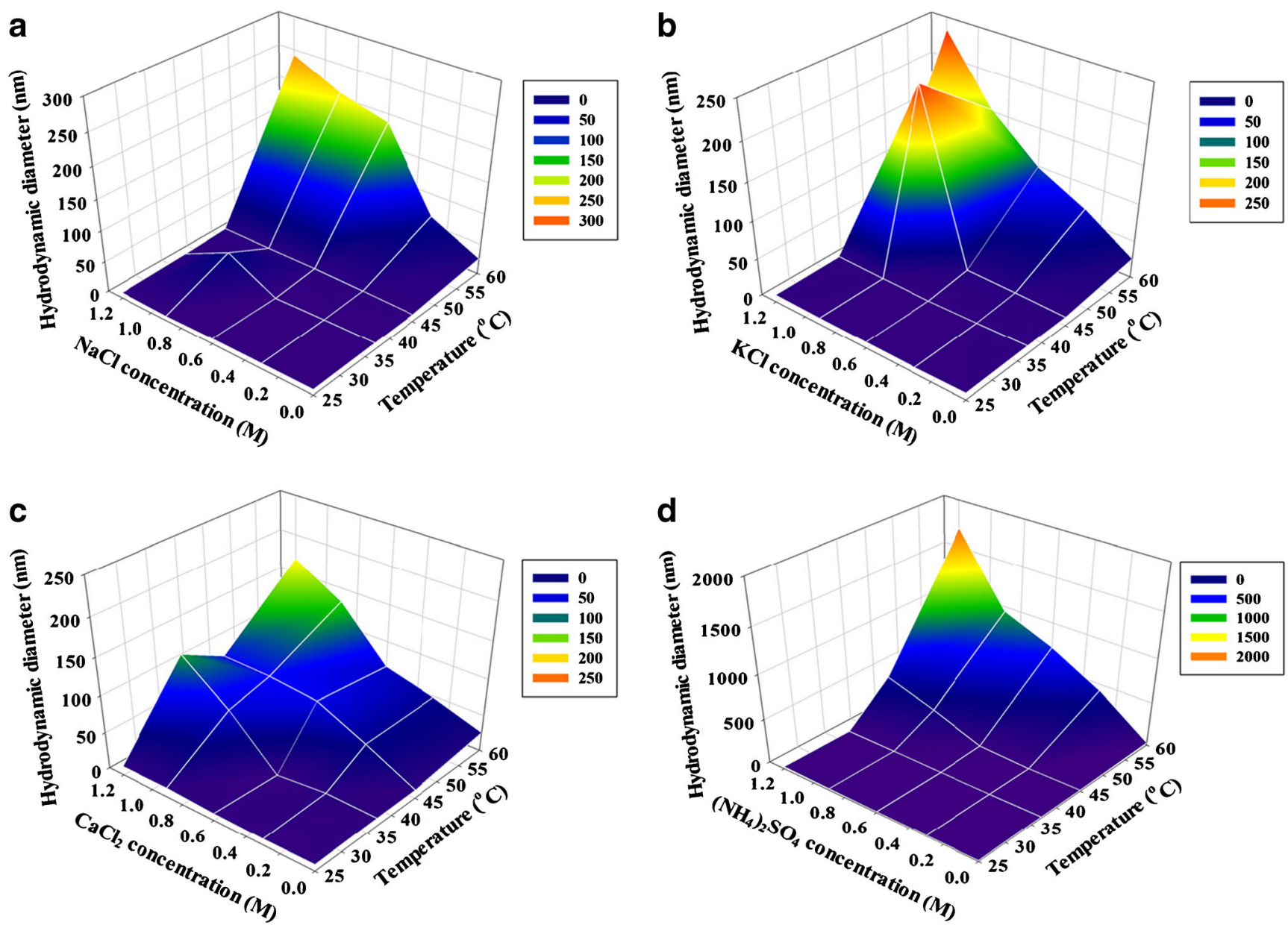

Fig. 6 Effect of temperature, salt type, and concentration on oligomerization of $L b$ GadB determined by DLS. a Sodium chloride (NaCl). b Potassium chloride $(\mathrm{KCl})$. c Calcium chloride $\left(\mathrm{CaCl}_{2}\right)$. d Ammonium sulfate $\left(\left(\mathrm{NH}_{4}\right)_{2} \mathrm{SO}_{4}\right)$ at different temperatures and salt concentrations at $\mathrm{pH} 7$

\section{Conclusion}

The $M W \mathrm{~s}$ and sizes of dimer and hexamer of $L b \mathrm{GadB}$ determined by AF4-UV-MALS-dRI were in good agreements with those from molecular modeling. The effects of temperature, salt type, and salt concentration on oligomerization of $L b \mathrm{GadB}$ were investigated using DLS. The hexamer content of $L b \mathrm{GadB}$ determined by deconvolution of UV/Vis detector response was $98 \%$, indicating the hexamer form is most stable at $\mathrm{pH}$ 6. The hexamer also showed high thermal stability (up to about $57^{\circ} \mathrm{C}$ ). This seems to be a new finding on oligomerization of $L b \mathrm{GadB}$. Results prove that AF4-UV-MALS-dRI is a powerful tool for separation of dimer, hexamer, and aggregates of $L b \mathrm{GadB}$ and also for monitoring of oligomerization of $L b \mathrm{GadB}$.

Acknowledgements The authors would like to thank Dr. Teresia Hallström for her assistance in using the instrument Prometheus NT.48 nanoDSF in a Demo and Prometheus NT.48 nanoDSF, Munich, Germany, for allowing us to use their instrument. The authors acknowledge the support provided by the National Research Foundation (NRF) of Korea (NRF-2013K2A3A1000086 and NRF-2016R1A2B4012105) and the Swedish Foundation for International Cooperation in Research and Higher Education (STINT).

\section{Compliance with ethical standards}

Conflict of interest The authors declare that they have no conflict of interest. There are no competing interests present and there are no patents, products in development, or marketed products to declare. Furthermore, we agree with the policies on sharing data and materials, as guide for authors.

Open Access This article is distributed under the terms of the Creative Commons Attribution 4.0 International License (http:// creativecommons.org/licenses/by/4.0/), which permits unrestricted use, distribution, and reproduction in any medium, provided you give appropriate credit to the original author(s) and the source, provide a link to the Creative Commons license, and indicate if changes were made.

\section{References}

1. Inoue K, Shirai T, Ochiai H, Kasao M, Hayakawa K, Kimura M, et al. Blood-pressure-lowering effect of a novel fermented milk containing $\gamma$-aminobutyric acid (GABA) in mild hypertensives. Eur J Clin Nutr. 2003;57(3):490-5. https://doi.org/10.1038/sj.ejcn. 1601555. 
2. Li H, Cao Y. Lactic acid bacterial cell factories for gammaaminobutyric acid. Amino Acids. 2010;39(5):1107-16. https:// doi.org/10.1007/s00726-010-0582-7.

3. Wu Q, Shah NP. High $\gamma$-aminobutyric acid production from lactic acid bacteria: emphasis on Lactobacillus brevis as a functional dairy starter. Crit Rev Food Sci Nutr. 2016;57(17):3661-72. https://doi. org/10.1080/10408398.2016.1147418.

4. Cho YR, Chang JY, Chang HC. Production of $\gamma$-aminobutyric acid (GABA) by Lactobacillus buchneri isolated from kimchi and its neuroprotective effect on neuronal cells. J Microbiol Biotechnol. 2007;17(1):104-9.

5. Yakabe T, Moore EL, Yokota S, Sui H, Nobuta Y, Fukao M, et al. Safety assessment of Lactobacillus brevis KB290 as a probiotic strain. Food Chem Toxicol. 2009;47(10):2450-3. https://doi.org/ 10.1016/j.fct.2009.07.001.

6. Astegno A, Capitani G, Dominici P. Functional roles of the hexamer organization of plant glutamate decarboxylase. Biochim Biophys Acta Proteins Proteomics. 2015;1854(9):1229-37. https:// doi.org/10.1016/j.bbapap.2015.01.001.

7. Hiraga K, Ueno Y, Oda K. Glutamate decarboxylase from Lactobacillus brevis: activation by ammonium sulfate. Biosci Biotechnol Biochem. 2008;72(5):1299-306. https://doi.org/10. 1271/bbb.70782.

8. Runyon JR, Williams SKR. Composition and molecular weight analysis of styrene-acrylic copolymers using thermal field-flow fractionation. J Chromatogr A. 2011;1218(38):6774-9. https://doi. org/10.1016/j.chroma.2011.07.076.

9. Striegel A, Yau WW, Kirkland JJ, Bly DD. Modern size-exclusion liquid chromatography: practice of gel permeation and gel filtration chromatography. 2nd ed. New York: Wiley; 2009.

10. Håkansson A, Ulmius M, Nilsson L. Asymmetrical flow field-flow fractionation enables the characterization of molecular and supramolecular properties of cereal $\beta$-glucan dispersions. Carbohydr Polym. 2012;87(1):518-23. https://doi.org/10.1016/j.carbpol. 2011.08.014

11. Cave RA, Seabrook SA, Gidley MJ, GiLbert RG. Characterization of starch by size-exclusion chromatography: the limitations imposed by shear scission. Biomacromolecules. 2009;10(8):224553. https://doi.org/10.1021/bm900426n.

12. Lee D, Williams SKR. Thermal field-flow fractionation and multiangle light scattering of polyvinyl acetate with broad polydispersity and ultrahigh molecular weight microgel components. J Chromatogr A. 2010;1217(10):1667-73. https://doi.org/10.1016/j. chroma.2010.01.035.

13. Schimpf ME, Caldwell K, Giddings JC. Field-flow fractionation handbook. In: Wahlund KG, editor. Chapter 18. Asymmetrical flow field-flow fractionation. New York: Wiley-Interscience; 2000. p. 279-94.

14. Litzen A, Wahlund KG. Improved separation speed and efficiency for proteins, nucleic acids and viruses in asymmetrical flow field flow fractionation. J Chromatogr. 1989;476:413-21. https://doi.org/ 10.1016/S0021-9673(01)93885-3.

15. Nilsson L. Separation and characterization of food macromolecules using field-flow fractionation: a review. Food Hydrocoll. 2013;30(1):1-11. https://doi.org/10.1016/j.foodhyd.2012.04.007.

16. Reschiglian P, Zattoni A, Roda B, Michelini E, Roda A. Field-flow fractionation and biotechnology. Trends Biotechnol. 2005;23(9): 475-83. https://doi.org/10.1016/j.tibtech.2005.07.008.
17. Yohannes G, Jussila M, Hartonen K, Riekkola ML. Asymmetrical flow field-flow fractionation technique for separation and characterization of biopolymers and bioparticles. J Chromatogr A. 2011;1218(27):4104-16. https://doi.org/10.1016/j.chroma.2010. 12.110 .

18. Krieger E, Vriend G. YASARA view - molecular graphics for all devices - from smartphones to workstations. Bioinformatics. 2014;30(20):2981-2. https://doi.org/10.1093/bioinformatics/ btu426.

19. Krieger E, Darden T, Nabuurs SB, Finkelstein A, Vriend G. Making optimal use of empirical energy functions: force-field parameterization in crystal space. Proteins Struct Funct Genet. 2004;57(4): 678-83. https://doi.org/10.1002/prot.20251.

20. Pettersen EF, Goddard TD, Huang CC, Couch GS, Greenblatt DM, Meng EC, et al. UCSF chimera - a visualization system for exploratory research and analysis. J Comput Chem. 2004;25(13):160512. https://doi.org/10.1002/jcc.20084.

21. Andersson M, Wittgren B, Wahlund K-G. Accuracy in multiangle light scattering measurements for molar mass and radius estimations. Model calculations and experiments. Anal Chem. 2003;75(16):4279-91. https://doi.org/10.1021/ac030128+.

22. Berry GC. Thermodynamic and conformational properties of polystyrene. I. Light-scattering studies on dilute solutions of linear polystyrenes. J Chem Phys. 1966;44(12):4550-64. https://doi.org/10. 1063/1.1726673.

23. Håkansson A, Magnusson E, Bergenståhl B, Nilsson L. Hydrodynamic radius determination with asymmetrical flow field-flow fractionation using decaying cross-flows. Part I. A theoretical approach. J Chromatogr A. 2012;1253:120-6. https://doi. org/10.1016/j.chroma.2012.07.029.

24. Magnusson E, Håkansson A, Janiak J, Bergenståhl B, Nilsson L. Hydrodynamic radius determination with asymmetrical flow fieldflow fractionation using decaying cross-flows. Part II. Experimental evaluation. J Chromatogr A. 2012;1253:127-33. https://doi.org/10. 1016/j.chroma.2012.07.005.

25. Schimpf ME, Caldwell K, Giddings JC. Field-flow fractionation handbook. In: Caldwell KD, editor. Chapter 5. Steric field-flow fractionation and the steric transition. New York: WileyInterscience; 2000. p. 79-94.

26. Schimpf ME, Caldwell K, Giddings JC. Field-flow fractionation handbook. In: Schure MR, Schimpf ME, Schettler PD, editors. Chapter 2. Retention-normal mode. New York: WileyInterscience; 2000. p. 31-48.

27. Einstein A. Über die von der molekularkinetischen Theorie der Wärme geforderte Bewegung von in ruhenden Flüssigkeiten suspendierten Teilchen. Ann Phys. 1905;322(8):549-60. https:// doi.org/10.1002/andp.19053220806.

28. Tanakai Y, Tsumoto K, Yasutake Y, Umetsu M, Yao M, Fukada H, et al. How oligomerization contributes to the thermostability of an archaeon protein: protein L-isoaspartyl-O-methyltransferase from Sulfolobus tokodaii. J Biol Chem. 2004;279(31):32957-67. https://doi.org/10.1074/jbc.M404405200.

29. Vogt G, Argos P. Protein thermal stability: hydrogen bonds or internal packing? Fold Des. 1997;2:S40-6. https://doi.org/10.1016/ S1359-0278(97)00062-X. 